\title{
The Physiological Response to Drawing and Its Relation to Attention and Relaxation
}

\author{
Gareth H. Loudon ${ }^{1,2}$, Gina M. Deininger ${ }^{1}$ \\ ${ }^{1}$ Centre for Creativity Ltd., Newport, UK \\ ${ }^{2}$ Cardiff School of Art \& Design, Cardiff Metropolitan University, Cardiff, UK \\ Email: gloudon@cardiffmet.ac.uk
}

How to cite this paper: Loudon, G.H. and Deininger, G.M. (2017) The Physiological Response to Drawing and Its Relation to Attention and Relaxation. Journal of Behavioral and Brain Science, 7, 111-124. https://doi.org/10.4236/jbbs.2017.73011

Received: October 4, 2016

Accepted: March 3, 2017

Published: March 6, 2017

Copyright ( 92017 by authors and Scientific Research Publishing Inc. This work is licensed under the Creative Commons Attribution International License (CC BY 4.0).

http://creativecommons.org/licenses/by/4.0/

Open Access

\begin{abstract}
The main purpose of this study was to analyze the physiological response of participants during a creative activity and compare the results to their physiological response during states of high attention and relaxation. Our interest was not only about the relationship between creativity and attention, but also about the role of valence and arousal. We used heart rate variability (HRV) as our physiological measure. We asked twenty-two participants to undertake three activities: a stroop test; a relaxation activity; and a drawing activity. After each activity, the participants were asked to reflect on their levels of attention, relaxation and enjoyment. The results showed significant physiological differences between the three activities: mean heart rate, $F(2,42)=8.96, p=$ 0.001 ; log-transformed low frequency HRV power, $\mathrm{F}(1.43,30.07)=18.12, \mathrm{p}<$ 0.001; and log-transformed high frequency HRV power, $\mathrm{F}(2,42)=6.25, \mathrm{p}=$ 0.004. Overall, the results suggested that participants had high levels of attention during the drawing activity, with positive valence. The results also suggested that participants' levels of arousal differed between the three activities. The implications of these results are described in the discussion.
\end{abstract}

\section{Keywords}

Creativity, Heart Rate Variability, Attention, Arousal, Valence

\section{Introduction}

We are interested in the factors and processes affecting creativity including the psychophysiological state of a person [1] [2] [3] [4]. One of our previous studies [5] analyzed the physiological response of participants during a creative task to investigate if a person's psychophysiological state was correlated with divergent thinking performance. We used heart rate variability (HRV) as our physiological measure. The results from the study showed a significant negative correlation 
between low frequency HRV power and the number of "divergent thinking" words generated. The result suggested that a person's psychophysiological state was correlated with their divergent thinking performance, and that attention might be an important factor. In this study, we investigated this further and analyzed a person's physiological response to another creative activity (specifically drawing) and how it compared to their physiological response during states of high attention and relaxation. Our interest was not only about the relationship between creativity and attention, but also about the role of valence and arousal.

\subsection{Creativity, Attention and Affect}

Sternberg and Lubart define creativity as the "ability to produce work that is both novel and appropriate" [6]. Another definition of creativity is "the ability to come up with ideas or artefacts that are new, surprising, and valuable" [7]. Csikszentmihalyi [8] highlighted that a commonality amongst creative people was that "they love what they do" and proposed that people entered a state of "flow" during creativity, where flow was characterized by high levels of concentration and positive affect. Other characteristics of flow include "immediate feedback to one's actions"; "a balance between challenges and skills"; and "no worry of failure". Csikszentmihalyi also highlighted that if the challenges were too great, this could create a feeling of frustration and anxiousness, and if the challenges were too easy, this could create a feeling of boredom. Davis [9] suggested that, in general, a positive mood enhanced creativity, while Silvia et al. [10] suggested that creative performance was related to motivation and effort. Affect can be described in terms of three major factors [11], one related to valence (pleasure-displeasure), one related to the level of arousal (engagement-disengagement), and one related to motivational intensity. However, arousal and motivational intensity are often correlated. Positive valence and high arousal are associated with emotional states such as excitement, negative valence and high arousal with anxiety and stress, positive valence and low arousal with relaxation, and negative valence and low arousal with emotional states such as drowsiness and sluggishness.

Peifer et al. [12] mapped Csikszentmihalyi's concept of flow to different emotion states and different levels of physiological arousal as shown in Figure 1 below. This relates to the Yerkes-Dodson law, mapping quality of performance to arousal level [13].

\subsection{Heart Rate Variability}

Heart rate variability (HRV) is the beat-to-beat variation in heart rate (HR) and can be measured from the variation in consecutive R-R intervals of the Electrocardiogram (ECG) or determined from the variation in consecutive pulse cycle intervals measured using techniques such as Photoplethysmography [14] [15] [16]. $\mathrm{HRV}$ is commonly regarded as a valuable non-invasive measure of Autonomic Nervous System (ANS) function [17] and a psychophysiological marker of mental and physical health [18].

The sympathetic and parasympathetic branches of the ANS regulate heart rate, 


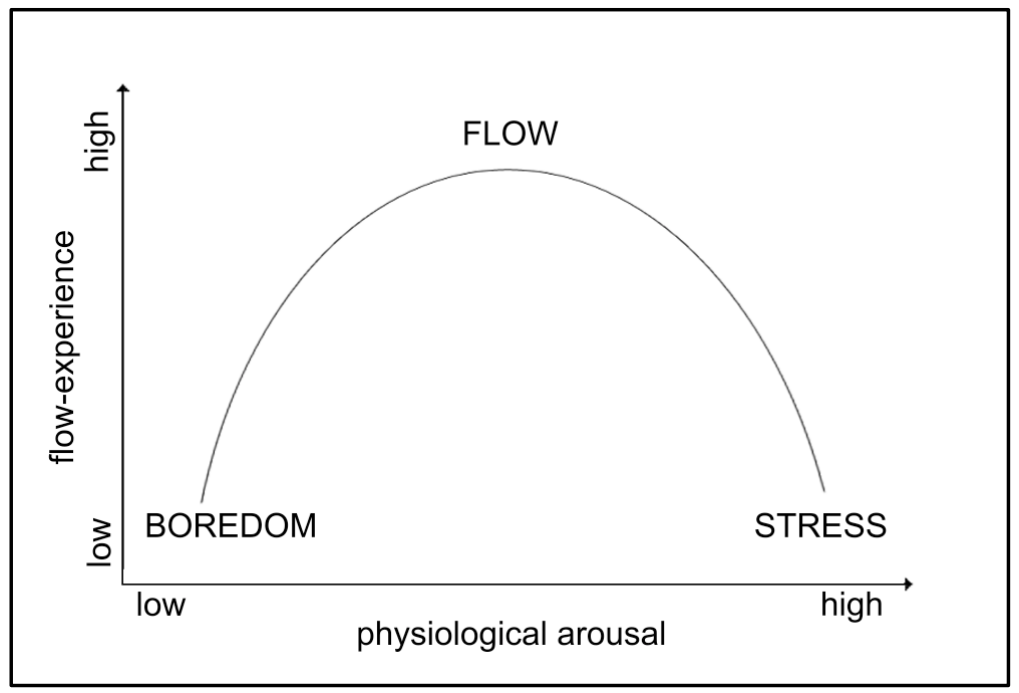

Figure 1. Physiological arousal and its relation to flow based on Peifer et al. [12].

with sympathetic activity causing an increase in heart rate and parasympathetic activity causing a decrease in heart rate. Past research on the frequency analysis of heart rate variability has found that HRV frequencies in the high frequency (HF) range $(0.15-0.4 \mathrm{~Hz})$ are usually associated with purely parasympathetic activity, while HRV frequencies in the low frequency (LF) range $(0.04-0.15 \mathrm{~Hz})$ are thought to be influenced by both parasympathetic and sympathetic activity [19] [20] [21]. The interpretation of HRV frequencies in the very low frequency (VLF) range $(<0.04 \mathrm{~Hz})$ is still not clear [17] [22]. When people are under stress, heart rate increases and HF HRV power reduces, indicating reduced parasympathetic activity [23] [24].

\subsection{Attention and HRV}

Kahneman [13] describes voluntary attention as "an exertion of [mental] effort in activities which are selected by current plans and intentions". Several research studies on the relation between mental workload and HRV have shown a reduction in HRV and an increase in heart rate during higher levels of mental effort [25] [26] [27]. Previous research has also shown that the $0.1 \mathrm{~Hz}$ component of $\mathrm{HRV}$ is sensitive to changes in mental effort [28] [29] with a reduction in power for higher levels of mental effort. However, small variations in mental effort are difficult to detect [30] [31] [32].

\subsection{Conclusion}

Research by Csikszentmihalyi [8] suggests that creativity is characterized by high levels of concentration and positive affect. Attention is associated with reductions in LF HRV power and higher levels of arousal. However mental effort is also often linked with increased levels of stress, with increases in heart rate and reductions in HF HRV power. As Kahneman [13] highlights, "the fundamental difficulty in the use of physiological techniques to measure effort is caused by the similarity between the physiological responses to mental effort and to stress". 


\section{Research Study Aims and Objectives}

One of the main aims in this study was to see if there was a difference between HR and HRV measures when a person undertakes a creative task versus a more stressful task requiring high levels of attention; and how the HR and HRV measures relate to a state when the person is relaxed.

Therefore, the two main objectives of this study were to:

a) Record and analyze the physiological response of participants during a creative drawing activity and compare their physiological responses when engaged with 1) a relatively stressful activity requiring high levels of attention and 2) an activity focused on relaxing.

b) Capture and analyze participants' reflections and thoughts about their own levels of attention, relaxation and enjoyment during the three activities.

The motivation behind these first two objectives was to get a deeper understanding of the relationship between creativity, attention and relaxation. There was also one secondary objective for this study. That was to investigate whether new HR watches, such as the Mio Alpha 2 [33] can be used to detect physiological differences between states of high attention and relaxation. The motivation behind this last objective was because these new HR sensors, using techniques such as Photoplethysmography, are becoming commonly available on the market and provide a simpler and more convenient way of estimating HRV. The major downside of using HR watches, however, is that previous research has shown that their capability of measuring HRV is significantly reduced due to their accuracy of recording pulse cycle intervals and the consequent averaging of pulse cycle interval data on the watches themselves to try and reduce the recording errors [34]. Mio Global themselves state that the "heart rate calculation of the Mio ALPHA is not based on instant R-R interval" [35].

\section{Preliminary Study}

Before trying to gain answers to the two main objectives, a small preliminary study was undertaken to analyze the differences between HRV estimates collected from a HR watch and from a sensor clipped to the ear.

\subsection{Methods}

\section{Procedure}

Pulse cycle interval data was collected from one of the authors (male, 48 years old) over a five-minute period. The recording took place at 10 a.m. (over 2 hours after breakfast) and the author was seated during the recording. Pulse cycle interval data were recorded from the wrist using the Mio Alpha 2 HR watch by Mio Global [33] and at the same time, pulse cycle interval data were also recorded using the emWave2 sensor by Heart Math [36] that was clipped to the author's ear.

Data Analysis and HRV Measures

All the pulse cycle interval data recorded, from both the Mio Alpha 2 watch and the emWave2 sensor, were converted into equidistant samples using an interpolation method. Power spectrum density (PSD) estimates of HRV were calculated 
using Welch's Fast Fourier Transform (FFT) method. PSD estimates were recorded for VLF, LF and HF ranges. In our preliminary study we set the VLF range from $0.00-0.04 \mathrm{~Hz}$, the $\mathrm{LF}$ range from $0.04-0.15 \mathrm{~Hz}$ and the $\mathrm{HF}$ range from $0.15-0.4 \mathrm{~Hz}$.

\subsection{Results}

Figure 2 below shows the pulse cycle interval data collected from the Mio Alpha 2 watch and the emWave 2 ear sensor. As can be seen, the pulse cycle interval data recorded from the Mio Alpha 2 watch has been averaged, which is equivalent to low-pass filtering the data. There is also a time delay in the corresponding data from the Mio Alpha 2 watch, also supporting the fact that the software in the Mio Alpha 2 watch is collecting several samples before taking an average.

Table 1 below shows the average HR, VLF Power, LF Power and HF Power calculated from the emWave2 ear sensor data and from the Mio Alpha 2 watch data. There was no difference between the estimates for average heart rate; there was a $7.8 \%$ decrease in the VLF Power estimates from the emWave 2 ear sensor to the Mio Alpha wrist sensor, a 69.3\% decrease for LF Power estimates and an 87.3\% decrease for HF Power estimates.

\subsection{Discussion}

It is clear from the small preliminary study that the HRV estimates calculated using the Mio Alpha 2 watch are severally affected by the averaging of pulse cycle

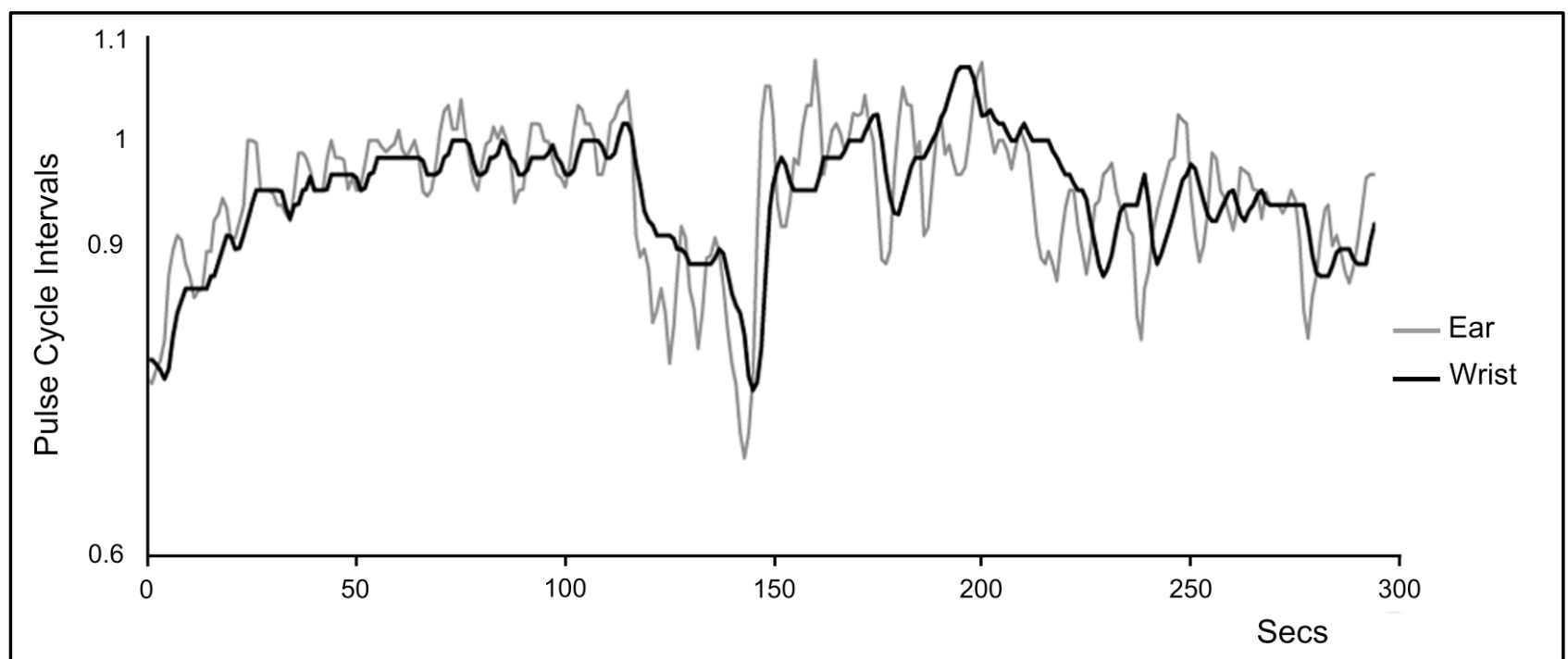

Figure 2. Pulse cycle interval data collected from the Mio Alpha 2 wristwatch (black line) and from the emWave 2 ear sensor (grey line).

Table 1. Physiological measures recorded with the emWave2 ear sensor and the Mio Alpha 2 watch.

\begin{tabular}{ccccc}
\hline \multirow{2}{*}{ Device } & \multicolumn{4}{c}{ Physiological Measures } \\
\cline { 2 - 4 } & HR $(\mathrm{bpm})$ & VLF Power $\left(\mathrm{ms}^{2}\right)$ & LF Power $\left(\mathrm{ms}^{2}\right)$ & HF Power $\left(\mathrm{ms}^{2}\right)$ \\
\hline emWave2 & 64.1 & 2272.5 & 1572.7 & 222.35 \\
Mio Alpha 2 & 64.1 & 2094.6 & 483.4 & 28.3 \\
\hline
\end{tabular}


interval data on the watch, and that the effect is most severe at the higher frequencies, with a very large percentage of HF power data lost. There is also a significant decrease in LF power. This might have an impact on being able to see changes in LF power normally associated with different levels of mental effort.

\section{Main Study}

To investigate the two main objectives (stated in the Research Study Aims and Objectives), 22 participants took part in three activities. The first activity involved undertaking a Stroop task using a random sequence of congruent and incongruent stimuli. The Stroop task has been extensively used to explore attention [37] because the interference between colour and word makes the task demanding and requires high levels of mental effort to keep performance in the task high. The second activity involved relaxing, whereby the participants were asked to close their eyes and relax. The third activity involved drawing. The participants were asked to draw something that was of interest to them. In this activity, the participants were also told that their drawing would not be assessed. Our motivation for including the drawing activity was because we regarded it as a creative task for several reasons: firstly, because the participants could create something new and of interest to them; because it was likely to be a pleasant activity, as the participants were all from an art and design background (and mostly enjoy drawing); because the participants were confident and skilled at drawing (so there was a balance between challenge and skill); because drawing gave immediate feedback to one's actions; and because there was little worry of failure (the work was not being assessed, and also because if they did not like what they were doing they could erase it and start again).

\subsection{Methods}

\section{Experimental Design}

Before each of the three activities, every participant was asked to sit quietly for three minutes. Each activity lasted two minutes. After each activity, participants were asked to reflect on their level of attention, relaxation and enjoyment during the activity. All comments from the participants were audio recorded. The experiment used a repeated measures design.

\section{Participants}

A total of 22 right-handed participants took part in the main study, 11 females and 11 males. Ethnic representation in the sample was 54.5\% White, $31.8 \%$ Asian, 9.1\% Arab and 4.5\% mixed ethnicity. Average age was 26.2 years old. The criteria for inclusion in the study were that participants were aged between 20 and 40 years of age; there was an equal number of males and females; they were either staff or students at the Cardiff School of Art and Design; and that they had a high level of confidence and skill in drawing. Within these criteria, simple random sampling was used. The Cardiff School of Art and Design's Research Ethics Committee gave ethics approval for the study. All participants gave their informed consent prior to their inclusion in the study. 


\section{Procedure}

The participants were tested individually, and each participant undertook the activities in a quiet room. The study was conducted during the morning between 10 a.m. and 1 p.m. and all participants were seated throughout. Pulse cycle interval data of each participant was recorded using the Mio Alpha 2 watch by Mio Global [33]. The sensor was attached to the participant's left wrist and the recording system checked for accuracy before the start of the tasks. Three minutes of baseline data was collected before the start of each activity where the participant was asked to sit quietly.

A computerized version of the Stroop task was used to present two words, red and green, in either the colour red or green. The software randomly selected the choice of word and colour. The participant had to select the correct colour answer from the two word options displayed at the bottom of the screen. Once the participant had made their choice, a new random combination of word and colour was presented. The software recorded the number of correct choices they made. The participants were given instructions on how to complete the Stroop task and were asked to try and get as high a score as they could in the two minutes.

The instructions given to each participant during the relaxation activity were to close their eyes and to put their right hand on their stomach so that they could feel their level of breathing and to relax. After two minutes of sitting with their eyes closed, the participants were asked to open their eyes.

For the last activity, each participant was given a blank sheet of A4 drawing paper and a selection of drawing implements including pens, pencils, crayons, chalk, charcoal, a pencil sharpener and an eraser. They were asked to draw whatever interested them and to use whatever drawing implements they liked. They were also told that there was no assessment of what they drew. After two minutes of drawing, the participants were asked to stop.

Data Analysis and HRV Measures

All the pulse cycle interval data recorded for each of the 22 participants were converted into equidistant samples using an interpolation method. Power spectrum density (PSD) estimates of HRV were calculated using Welch's Fast Fourier Transform (FFT) method. PSD estimates were recorded for LF and HF ranges. In our main study, we set the LF range from $0.07-0.15 \mathrm{~Hz}$ and the $\mathrm{HF}$ range from $0.15-0.4 \mathrm{~Hz}$. The LF range was set from $0.07-0.15 \mathrm{~Hz}$ because our main area of interest in the LF range was around $0.1 \mathrm{~Hz}$ (due to its sensitivity to mental effort). The mean heart rate during each of the activities was also recorded.

Both the PSD estimates for the LF and HF ranges were natural-log transformed to obtain Gaussian distributions [38]. Statistical analysis was conducted using SPSS Version 22. An analysis of variance (ANOVA) was conducted to study the difference in means between the physiological measures recorded for the participants in the three activities. The alpha level was set at 0.05 for the classification of significant difference. Based on Cohen [39], we interpreted effect size as small when $r=0.1$; medium when $r=0.3$; and large when $r=0.5$. 
All the reflections by participants (captured after each activity) on their level of attention, relaxation and enjoyment during the activity were audio recorded. All the audio recordings of the participants' comments were transcribed and a themed analysis undertaken related to the topics of attention, relaxation and enjoyment.

\subsection{Results}

\section{Physiological Data Analysis}

Table 2 below shows the physiological measures recorded for the 22 participants across the three activities, including the mean and standard deviation (SD) for heart rate (HR), log-transformed absolute LF power (ln LF) and log-transformed absolute HF power (ln HF).

Firstly, analyzing the mean heart rate data across the three activities, Maulchy's test indicated that the assumption of sphericity was not violated, $\chi^{2}(2)=2.74, \mathrm{p}=$ 0.254 . The results showed that the mean heart rate data was significantly affected by the activity, $\mathrm{F}(2,42)=8.96, \mathrm{MSE}=30.40, \mathrm{p}=0.001$, with a small effect size, $\omega^{2}=0.04$. Comparing pairs of activities, the mean heart rate for the Stroop task was significantly higher than the drawing activity, $\mathrm{F}(1,21)=5.37, \mathrm{MSE}=29.30$, $\mathrm{p}=0.03$, with a medium effect size, $\mathrm{r}=0.45$, and significantly higher than the relaxation activity, $\mathrm{F}(1,21)=13.48, \mathrm{MSE}=40.33, \mathrm{p}=0.001$ with a large effect size, $r=0.62$. The mean heart rate for the drawing activity was also significantly higher than the relaxation activity, $\mathrm{F}(1,21)=5.39, \mathrm{MSE}=21.57, \mathrm{p}=0.03$, with a medium effect size, $r=0.45$.

Analyzing the mean log-transformed absolute low frequency power (ln LF) across the three activities, Maulchy's test indicated that the assumption of sphericity was violated, $\chi^{2}(2)=10.10, p=0.006$, therefore, Greenhouse-Geisser corrected tests were reported $(\varepsilon=0.72)$. The results showed that ln LF was significantly affected by the activity, $\mathrm{F}(1.43,30.07)=18.12$, MSE $=0.88, \mathrm{p}<0.001$, with a large effect size, $\omega^{2}=0.20$. Comparing pairs of activities, $\ln$ LF for the Stroop task was not significantly different to the drawing activity, $\mathrm{F}(1,21)=0.16$, MSE $=0.33$, but was significantly lower than the relaxation activity, $\mathrm{F}(1,21)=18.00$, MSE $=1.00, p<0.001$ with a large effect size, $r=0.68 . \ln$ LF for the drawing activity was also significantly lower than the relaxation activity, $\mathrm{F}(1,21)=28.71$, MSE $=0.56, p<0.001$, with a large effect size, $r=0.76$.

Analysing the mean log-transformed absolute high frequency power (ln HF) across the three activities, Maulchy's test indicated that the assumption of spheric-

Table 2. Physiological measures for the three activities.

\begin{tabular}{rcccccc}
\hline \multirow{2}{*}{ Measure } & \multicolumn{2}{c}{ Stroop Task } & \multicolumn{2}{c}{ Relaxation } & \multicolumn{2}{c}{ Drawing } \\
\cline { 2 - 6 } & Mean & SD & Mean & SD & Mean & SD \\
\hline HR (bpm) & 84.40 & 16.04 & 77.37 & 12.82 & 80.62 & 12.33 \\
$\ln$ LF $\left(\mathrm{ms}^{2}\right)$ & 3.74 & 1.09 & 5.02 & 1.28 & 3.81 & 1.00 \\
$\ln \mathrm{HF}\left(\mathrm{ms}^{2}\right)$ & 2.24 & 1.03 & 2.77 & 1.11 & 2.32 & 0.81 \\
\hline
\end{tabular}


ity was not violated, $\chi^{2}(2)=1.81, \mathrm{p}=0.405$. The results showed that $\ln \mathrm{HF}$ was significantly affected by the activity, $\mathrm{F}(2,42)=6.25, \mathrm{MSE}=0.28, \mathrm{p}=0.004$, with a small effect size, $\omega^{2}=0.04$. Comparing pairs of activities, ln HF for the Stroop task was not significantly different to the drawing activity, $\mathrm{F}(1,21)=0.21$, MSE $=0.31$, but was significantly lower than the relaxation activity, $\mathrm{F}(1,21)=8.93$, $\mathrm{MSE}=0.34, \mathrm{p}=0.007$, with a large effect size, $\mathrm{r}=0.55$. ln HF for the drawing activity was also significantly lower than the relaxation activity, $F(1,21)=10.99$, $\mathrm{MSE}=0.20, \mathrm{p}=0.003$, with a large effect size, $\mathrm{r}=0.59$.

\section{Qualitative Analysis}

The feedback from the participants on their level of attention, relaxation/stress and enjoyment during the activity is presented below, firstly in relation to the Stroop task, followed by the relaxation and drawing activities.

Participants generally found the Stroop task stressful, especially initially ("Initially I was more stressed", "Stressful, consistent the whole way through", "I felt my heart beating, like having an exam"). Making mistakes during the task also kept some of their stress levels high ("When I made a mistake, I started to panic"). However, several of the participants developed strategies to try and minimize distractions, to narrow their attention, to block out the word, and focus on the colour only ("I tried to find a method to not be distracted", "I was whispering the word, it was a very mental process", "I tried to mentally focus on the colour and block out the text"). Most commented that they felt their attention was high and they were very focused ("I was on it, focused, and I found myself being competitive", "Attention was probably as high as it is likely to be", "It was a case of focusing on that task, I wasn't thinking about anything else"). A small number of the participants also actually enjoyed the task towards the end as they felt they were getting better at the task and that was rewarding ("At first I was stressed, then I started to be relaxed, then I enjoyed it", "I felt a lot calmer as I saw I started to get things right").

Participants were generally quite relaxed during the relaxation activity ("I could have gone back to sleep", "That was quite relaxing. For a minute I forgot I was here. I don't know, I just switched off”, "Just a nice relaxed feeling”), however, some found it hard to relax initially ("At first, it was very hard for me to relax, [but at the end] I feel like, 'is it two minutes?'”, "I found it quite hard to relax at the beginning", "The last minute I was most relaxed"). Attention levels were generally reported as low with some saying that as they got more relaxed, their minds started to wander and ideas popped into their heads ("I was just blank", "My mind started to wander about half way through"). However, a small number of participants actually focused on something to help them relax ("I was paying attention to the clock the majority of the time", "I counted to ten and then back again. As soon as I did that I think I was pretty much going into a meditative state"). Generally participants enjoyed the relaxation activity ("It was a lot nicer than the first one [Stroop task]").

Most participants reported that they found the drawing activity quite relaxing ("I felt relaxed all the time") and this was partly due to the fact that the work was 
not being assessed ("My relaxation was probably good because I wasn't worrying about the outcome of the drawing", "I found that quite relaxing, there was no pressure on being judged"), but also because it was an activity the participants enjoy and they are good at ("You are not evaluating me, so I am free to do whatever I want, so this is a comfortable way for me to work. So I think it was very enjoyable, I was having fun", "Rather enjoyable", "It is not an unpleasant thing to be asked to do", "Drawing I find quite natural anyway"). However, a small number of participants were not fully relaxed at the beginning of the task as a blank sheet of paper opened up so many possibilities, and some were not sure what to draw ("I find a blank page quite intimidating but I break that down by the chalk. As soon as the chalk is on I can relax", "Where do I start"). Attention levels were generally reported as high ("I was very focused", "Attention quite high", "It was just completely free concentrating on hand movements").

\subsection{Discussion}

Feedback from the participants suggests that during the first activity (the Stroop Task), they had, on average, a high level of attention and a high level of stress. During the relaxation activity, they had, on average, a low level of attention and a high level of relaxation. They also reported, in general, that they enjoyed the relaxation activity. During the drawing activity, participants reported that, on average, they had a high level of attention and a low level of stress. Again they reported, in general, that they enjoyed the drawing activity.

When combing the results from the physiological data and the participant feedback, the Mio Alpha $2 \mathrm{HR}$ watch does seem to be able to detect physiological differences between states of high attention and relaxation, even though large amounts of HRV data is lost by using such a device (as indicated from the preliminary study). We believe this is an important finding, as HR watches, such as the Mio Alpha 2, provide a simple and convenient way of estimating heart rate. There were significant differences between the physiological measurements (HR, ln LF and ln HF) from the Stroop Task and the relaxation activity. The results were also in line with previous research findings, with increases in HR for the Stroop Task and reductions in ln LF, associated with increased mental effort. For the relaxation activity, HR reduced and overall HRV power (ln LF and ln HF) increased.

When analyzing the physiological response of participants during the creative drawing activity, compared with their physiological response when engaged in the Stroop Task, there were some similarities and also some differences. In LF and $\ln \mathrm{HF}$ were not significantly different for the two activities, however, the HR was significantly lower for the creative drawing activity. When combining these results with the participant feedback, it suggested that attention levels were not significantly different between the two activities and that attention levels were high when the participants were drawing. It also suggested that, on average, participants were more relaxed during the drawing activity, they enjoyed the activity more, and their level of arousal was lower. 
There were significant differences between the physiological measurements (HR, ln LF and ln HF) from the creative drawing activity and the relaxation activity, with HR being higher for the drawing activity, and ln LF and ln HF being lower. Combined with the participant feedback, it suggested that participants were not as relaxed in the drawing activity compared with the relaxation activity, and they had higher levels of arousal and higher levels of attention.

The results from this study seem to support the idea that people do enter a state of concentration with positive affect during a creative activity (such as drawing), that Csikszentmihalyi [8] described as "flow"; and that this state is distinctive from pure relaxation, with higher levels of arousal. The results from the study also seem to map to the ideas by Peifer et al. [12] on flow. However, this needs further investigation. The results provide some further evidence in support of the findings from our previous study [5] that a person's physiological state is correlated with their divergent thinking performance, and that attention might be an important factor.

It is also worth raising the question about potential differences between the type of attention taking place during the Stroop task and the creative drawing activity and the role of valence and arousal. Feedback from participants on the Stroop task suggested that they narrowed their attention to reduce interference and distractions. No such comments were made about the drawing activity.

Kahneman [13] highlighted that "high arousal causes attention to be concentrated on the dominant aspects of the situation at the expense of other aspects" and that "complex tasks often require attention to varied cues, and are therefore, performed poorly when arousal is high". Harmon-Jones et al. [11] also found that high levels of motivational intensity (that can result in high levels of arousal) narrowed cognitive scope.

Creative activities are often complex in nature and therefore, it would be beneficial to undertake further investigation into the role of attention to see how it impacts on creative performance. We also feel it is important to consider the role of "dynamic movement" in creativity [3] [4] and not just think of creativity as being associated with one static state. This includes the movement between different affective states.

\section{Limitations}

By using the Mio Alpha $2 \mathrm{HR}$ watch for recording HRV, a significant amount of HRV information was lost. This lost HRV data might have provided further insights. It might also have changed the significance of the results reported. However, one of our main motivations was to see if HR watches, such as the Mio Alpha 2, could be used to differentiate between high levels of attention and relaxation, due to their convenience of use. It should also be noted that only 22 participants were involved in the study, so the conclusions drawn at this stage can only be tentative.

\section{Future Directions}

We plan to look into the relationship between attention and creativity in more 
depth exploring how the level of arousal affects the narrowing of attention and the impact that has on creative performance. We also plan to conduct further studies to investigate if the real-time biofeedback and visualization of HRV measures, recorded from HR watches, can be used to track and help improve the attention and relaxation levels for individuals.

\section{Acknowledgements}

Gareth Loudon would like to thank Innovate UK for supporting the work.

\section{References}

[1] Deininger, G.M., Loudon, G.H. and Norman, S. (2012) Modal Preferences in Creative Problem Solving, Cognitive Processing, 13, 147-150. https://doi.org/10.1007/s10339-012-0479-3

[2] Deininger, G.M. (2013) Does State of Being and Dynamic Movement have a Relationship with Creativity? PhD Thesis, Cardiff Metropolitan University, Cardiff.

[3] Loudon, G.H., Deininger, G.M. and Gordon, B.S. (2012) Play, Autonomy and the Crea-tive Process. In: Duffy, A., Nagai, Y. and Taura, T., Eds., Proceedings of the 2nd International Conference on Design Creativity, the Design Society, 87-96.

[4] Loudon, G.H. and Deininger, G.M. (2014) A New Model for Supporting Creativity in Research Organizations. In: Schimpf, S., Ed., Proceedings of the $R \& D$ Management Conference, Fraunhofer IAO, Germany, 93-100.

[5] Loudon, G. and Deininger, G. (2016) The Physiological Response during Divergent Thinking. Journal of Behavioral and Brain Science, 6, 28-37.

https://doi.org/10.4236/jbbs.2016.61004

[6] Sternberg, R.J. and Lubart, T.I. (1999) The Concept of Creativity: Prospects and Paradigms. In: Sternberg, R.J., Ed., Handbook of Creativity, Cambridge University Press, Cambridge, 169-186.

[7] Boden, M.A. (2004) The Creative Mind: Myths and Mechanisms. 2nd Edition, Routledge, London.

[8] Csíkszentmihályi, M. (1996) Creativity: Flow and the Psychology of Discovery and Invention. Harper Collins, New York.

[9] Davis, M.A. (2009) Understanding the Relationship between Mood and Creativity: A Meta-Analysis. Organizational Behavior and Human Decision Processes, 108, 25 38. https://doi.org/10.1016/j.obhdp.2008.04.001

[10] Silvia, P.J., Beaty, R.E., Nusbaum, E.C., Eddington, K.M. and Kwapil, T.R. (2014) Creative Motivation: Creative Achievement Predicts Cardiac Autonomic Markers of Effort during Divergent Thinking. Biological Psychology, 102, 30-37. https://doi.org/10.1016/j.biopsycho.2014.07.010

[11] Harmon-Jones, E., Gable, P.A. and Price, T.F. (2013) Does Negative Affect Always Narrow and Positive Affect Always Broaden the Mind? Considering the Influence of Motivational Intensity on Cognitive Scope. Current Directions in Psychological Science, 22, 301-307. https://doi.org/10.1177/0963721413481353

[12] Peifer, C., Schulz, A., Schächinger, H., Baumann, N. and Conny, H.A. (2014) The Relation of Flow Experience and Physiological Arousal Under Stress-Can U Shape It? Journal of Experimental Social Psychology, 53, 62-69. https://doi.org/10.1016/j.jesp.2014.01.009

[13] Kahneman, D. (1973) Attention and Effort. Prentice Hall, Englewood Cliffs.

[14] Schäfer, A. and Jan Vagedes, J. (2013) How Accurate Is Pulse Rate Variability as an 
Estimate of Heart Rate Variability? A Review on Studies Comparing Photoplethysmographic Technology with an Electrocardiogram. International Journal of Cardiology, 166, 15-29. https://doi.org/10.1016/j.ijcard.2012.03.119

[15] Gil, E., Orini, M., Bailón, R., Vergara, J.M., Mainardi, L. and Laguna, P. (2010) Photoplethysmography Pulse Rate Variability as a Surrogate Measurement of Heart Rate Variability during Non-Stationary Conditions. Physiological Measurement, 31, 1271-1290. https://doi.org/10.1088/0967-3334/31/9/015

[16] Lu, G., Yang, F., Taylor, J.A. and Stein, J.F. (2009) A Comparison of Photoplethysmography and ECG Recording to Analyse Heart Rate Variability in Healthy Subjects. Journal of Medical Engineering \& Technology, 33, 634-641. https://doi.org/10.3109/03091900903150998

[17] Xhyheri, B., Manfrini, O., Mazzolini, M., Pizzi, C. and Bugiardini, R. (2012) Heart Rate Variability Today. Progress in Cardiovascular Diseases, 55, 321-331. https://doi.org/10.1016/j.pcad.2012.09.001

[18] Kemp, A.H. and Quintana, D.S. (2013) The Relationship between Mental and Physical Health: Insights from the Study of Heart Rate Variability. International Journal of Psychophysiology, 89, 296-304. https://doi.org/10.1016/j.ijpsycho.2013.06.018

[19] Akselrod, S., Gordon, D., Madwed, J.B., Snidman, N.C., Shannon, D.C. and Cohen, R.J. (1985) Hemodynamic Regulation: Investigation by Spectral Analysis. American Journal of Physiology, 18, 867-875.

[20] Koh, J., Brown, T.E., Beightol, I.A., Ha, C.Y. and Eckberg, D.L. (1994) Human Autonomic Rhythms: Vagal Cardiac Mechanisms in Tetraplegia Subjects. Journal of Physiology, 474, 481-495. https://doi.org/10.1113/jphysiol.1994.sp020039

[21] Reyes Del Paso, G.A., Langewitz, W., Mulder, L.J.M., Van Roon, A. and Duschek, S. (2013) The Utility of Low Frequency Heart Rate Variability as an Index of Sympathetic Cardiac Tone: A Review with Emphasis on a Reanalysis of Previous Studies. Psychophysiology, 50, 477-487. https://doi.org/10.1111/psyp.12027

[22] Berntson, G., Bigger Jr., J., Eckberg, D., Grossman, P., Kaufmann, P., Malik, M., Nagaraja, H., Porges, S., Saul, J., Stone, P. and van der Molen, M. (1997) Heart Rate Variability: Origins, Methods, and Interpretive Caveats. Psychophysiology, 34, 623648. https://doi.org/10.1111/j.1469-8986.1997.tb02140.x

[23] Dishman, R.K., Nakamura, Y. and Garcia, M.E. (2000) Heart Rate Variability, Trait Anxiety, and Perceived Stress among Physically Fit Men and Women. International Journal of Psychophysiology, 37, 121-133. https://doi.org/10.1016/S0167-8760(00)00085-4

[24] Friedman, B.H. (2007) An Autonomic Flexibility-Neurovisceral Integration Model of Anxiety and Cardiac Vagal Tone. Biological Psychology, 74, 185-199. https://doi.org/10.1016/j.biopsycho.2005.08.009

[25] Althaus, M., Mulder, L.J.M., Mulder, G., Van Roon, A.M. and Minder, R.B. (1998) Influence of Respiratory Activity on the Cardiac Response Pattern to Mental Effort. Psychophysiology, 35, 420-430. https://doi.org/10.1111/1469-8986.3540420

[26] Hansen, A.L., Johnsen, B.H. and Thayer, J.F. (2003) Vagal Influence on Working Memory and Attention. International Journal of Psychophysiology, 48, 263-274. https://doi.org/10.1016/S0167-8760(03)00073-4

[27] Van Roon, A.M., Mulder, L.J.M., Veldman, J.B.P. and Mulder, G. (1995) Beat-toBeat Blood-Pressure Measurements Applied in Studies on Mental Workload. Homeostasis, 36, 3316-3324.

[28] Aasman, J., Mulder, G. and Mulder, L.J.M. (1987) Operator Effort and the Measurement of Heart Rate Variability. Human Factors, 29, 161-170.

[29] Tattersall, A.J. and Hockey, G.R.J. (1995) Level of Operator Control and Changes in 
Heart Rate Variability during Simulated Flight Maintenance. Human Factors, 37, 682-698. https://doi.org/10.1518/001872095778995517

[30] Jorna, P.G.A.M. (1992) Spectral Analysis of Heart Rate and Psychological State: A Review of Its Validity as a Workload Index. Biological Psychology, 34, 237-257. https://doi.org/10.1016/0301-0511(92)90017-O

[31] Nickel, P. and Nachreiner, F. (2002) The Suitability of the $0.1 \mathrm{~Hz}$ Component of Heart Rate Variability for the Assessment of Mental Workload in Real and Simulated Work Situation. In: de Waard, D., Brookhuis, K.A., Moraal, J. and Toffetti, A., Eds., Human Factors in Transportation, Communication, Health and the Workplace, Shaker, Maastricht, 317-334.

[32] Veltman, J.A. and Gaillard, A.W.K. (1996) Physiological Indices of Workload in a Simulated Flight Task. Biological Psychology, 42, 323-342.

https://doi.org/10.1016/0301-0511(95)05165-1

[33] Mio Alpha 2 (2016) Mio Alpha 2 Heart Rate Monitor Watch. http://www.mioglobal.com/EN-UK/Mio-ALPHA-2-Heart-Rate-Watch/Product.asp

[34] Parak, J. and Korhonen, I. (2014) Evaluation of Wearable Consumer Heart Rate Monitors Based on Photopletysmography. 36th Annual International Conference of the IEEE Engineering in Medicine and Biology Society, Chicago, 26-30 August, 3670-3673. https://doi.org/10.1109/embc.2014.6944419

[35] Mio Global (2016) Mio Alpha 2 User Guide. http://www.mioglobal.com/docs/mio_alpha2_complete-user-guide_en.pdf

[36] emWave 2 (2016) emWave2 Heart Rate Monitor. http://www.heartmathstore.com/category/emWave2/

[37] MacLeod, C. and MacLeod, C. (2005) The Stroop Task: Indirectly Measuring Concept Activation. In: Wenzel, A. and Rubin, D.C., Eds., Cognitive Methods and Their Application to Clinical Research, American Psychological Association, Washington, 13-16. https://doi.org/10.1037/10870-001

[38] Van Roon, A.M. (1998) Short-Term Cardiovascular Effects of Mental Tasks. PhD Thesis, University of Groningen, Groningen.

[39] Cohen, J. (1988) Statistical Power Analysis for the Behavioral Sciences. 2nd Edition, Lawrence Erlbaum Associates, Hillsdale.

\section{Submit or recommend next manuscript to SCIRP and we will provide best service for you:}

Accepting pre-submission inquiries through Email, Facebook, LinkedIn, Twitter, etc. A wide selection of journals (inclusive of 9 subjects, more than 200 journals)

Providing 24-hour high-quality service

User-friendly online submission system

Fair and swift peer-review system

Efficient typesetting and proofreading procedure

Display of the result of downloads and visits, as well as the number of cited articles

Maximum dissemination of your research work

Submit your manuscript at: http://papersubmission.scirp.org/

Or contact jbbs@scirp.org 